\title{
Cultivating Professional Skills Across The Business Curriculum
}

Jerome Witt (E-mail: wittj@philau.edu), Philadelphia University

\begin{abstract}
This university has devised a scheme for developing a set of professional skills in its students by means of a series of experiential activities incorporated into business core courses. Six areas of competency were identified as crucial for all business graduates: analytical skills, communication skills, ethical discernment, global perspectives, information technology/literacy and professionalism. The program overlays a set of lessons and experiences in the thirteen courses that comprise the business core, i.e. those courses required for all business majors.
\end{abstract}

\section{Introduction}

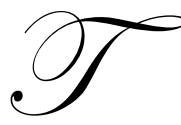

he School of Business Administration at Philadelphia University has identified a set of skills that are crucial for all business graduates and devised a strategy for developing those proficiencies in its students. By means of a series of varied developmental experiences delivered in the thirteen courses of the business core, the project develops students' analytical skills, communication skills, ethical discernment, global perspectives, information technology/literacy, and professionalism.

The project began in October 1996 with a charge from the dean of the School of Business Administration to investigate the need for updating the business core (i.e. the thirteen courses required for all business majors) in the context of student learning outcomes. A committee was formed, comprised of both junior and senior faculty representing the various functional disciplines that are included in the core: accounting, management, finance, information systems, economics, operations management, statistics and marketing. Adopting a holistic approach, the committee considered what we wanted graduates to look like when they completed a business degree from our institution. We were particularly impressed with the findings of a 1993-95 project conducted by eleven "partnership schools" and the Ernst \& Young Foundation (1) that found that employers are looking for the following attributes in business school graduates:

$\begin{array}{ll}- & \text { Communication skills } \\ - & \text { Interpersonal skills } \\ \text { - } & \text { Computer skills } \\ \text { - } & \text { Leadership skills } \\ & \text { Problem solving skills }\end{array}$

The focus of our work became learning outcomes in these kinds of personal and interpersonal skills rather than the functional areas. After considerable discussions, six areas of competency were identified as crucial for our graduates: analytical skills, communication skills, ethical discernment, global perspectives, information technology/literacy, and professionalism. Ultimately it was decided that we would develop a strategy for overlaying a series of learning experiences in each of the 13 core courses. (It should be stated here that at this university business majors begin taking the business core courses in their freshman year.) 


\section{Implementation}

In implementing the strategy one major obstacle was encountered. The sequence in which students were taking the thirteen core courses was inconsistent across the business majors and was only loosely prescribed within each major. At that time there were eleven majors in the School of Business Administration.

To address these inconsistencies, the first step was to develop a uniform sequence for the core courses that would meet with the approval of the faculty. Course requirements and sequencing in each major were reviewed to assure that any new sequencing of the core courses would provide the needed prerequisites to courses in the major early enough to accommodate the sequence of courses within the major. The task was made more challenging because of the already established and relatively inflexible sequence of general education courses across the four years.

Working within these constraints we found that it would be necessary to allow for some inconsistencies in the sequencing of core courses. As a result we characterized the proposed sequence as "recommended" with the objective of keeping the exceptions to a minimum. The two courses in the core that were identified as the best to "float" were Business Law I and Macroeconomics. They were chosen because a) they are not prerequisite for any course in a major, and b) it was felt these subjects, more than any others, would logically fit anywhere in the curriculum.

At each step during the process the proposed changes were presented to the business faculty for preliminary approval. Faculty in each discipline was asked to review and sign-off on the new sequencing in their area. After unanimous approval of the changes, the advising check sheets for all majors were redesigned and the appropriate changes were made to the next catalog.

The present recommended course sequence is as follows:

- $\quad$ First Year

- Introduction to Information Systems

- $\quad$ Principles of Marketing

- $\quad$ Financial Accounting

- $\quad$ Managerial Accounting

- $\quad$ Second Year

- $\quad$ Principles of Management

- $\quad$ Statistics I

- $\quad$ Statistics II

- $\quad$ Macroeconomics (*)

- Microeconomics

- $\quad$ Third Year

- $\quad$ Financial Management

- $\quad$ Business Law $(*)$

- $\quad$ Fourth Year

- Operations Management

- $\quad$ Business Policy and Strategy

(*) These courses are moved to different years in some majors. 


\section{Development Of Activities}

The next step was to develop specific learning experiences to cultivate the various skills areas. The plan was to phase in the program beginning with five first-year courses in 1999-2000, adding second year courses in 2000-2001, and so on. Freshmen entering in fall 2000 would be the first cohort to experience the entire program. The activities developed for the first year were designed primarily to accomplish awareness of the importance of and fundamental instruction in each skill area and to provide basic vocabulary and tools in each area. Activities in the second and subsequent years are for the most part integrative in that each involves the application of a combination of skills.

For activities during the first year, determining which course would house each activity was in some cases difficult. Where there was a clear synergy between the activity and the course (i.e. Global Perspectives in Financial Accounting, Information Technology/Literacy and Analytical Skills in Introduction to Information Systems and Ethical Discernment in Managerial Accounting) the decision was easy. In the other cases, where there was not a clear synergy with course content (Communication Skills and Professionalism), it was necessary to simply overlay the activities in the remaining first year courses. Since student presentations were already being required in most sections of Principles of Marketing, the Communication Skills and Professionalism activities were housed there.

\section{Articulation Of Outcomes Objectives}

For each activity there is a handout for the students as well as a makeup handout for students who missed or did not complete the activity. Included in the handouts for all activities is an explanation of the overall project and a customized statement of outcomes objectives for the specific activity.

This explanation of the overall project (which is the same for all activities) explains that the SBA uses the business core courses to accomplish the development of professional skills:

This course is a part of the Business Core which is comprised of 13 courses that are taken by all business majors. Courses in the Business Core have a dual purpose:

- To teach a specific part of the basic "body of knowledge" all business students need to know, and

- To make distinct contributions to students' overall professional and personal growth in one or more of six major areas: analytical skills, communication skills, computer technology, ethical discernment, global perspectives, and professionalism.

The SBA considers both the knowledge and the personal and professional growth to be essential parts of preparing students for entry, advancement and success in the business world.

As an example of a statement of outcomes objectives for a specific activity, in this case communication skills, the statement of Outcomes Objectives is:

Outcomes Objectives: This is the first of a series of activities designed to contribute to the development of your communication skills. The four-year goals in this outcomes area are to help you develop the oral presentation and communication skills that are appropriate and expected in any business or professional environment. Among the specific outcomes are an understanding of the nature of communication, ease with making an oral presentation, listening skills, and the development of your own professional communication style. Successive activities throughout your university experience will help you to learn, cultivate and practice these valuable skills. This first activity is focused on introducing the nature and importance of communications in the business environment and the skill of listening. 


\section{Administration And Feedback}

A concerted effort was made to assure that each activity is conducted uniformly in all sections of the course. Because various faculty are involved from one semester to the next, all activities were structured and documented to require only minimal orientation and demands on the professors. An administrator oversees and coordinates the program. For each activity professors are given a packet of materials at the appropriate time during the semester. The packet includes a transmittal sheet, instructor's notes, a sufficient supply of student handouts (including makeup handouts for students who miss the activity) and a faculty feedback form. The transmittal sheet, in addition to identifying the contents of the packet, provides a tear-off slip to be returned to the administrator with dates and room numbers for each section. The administrator arranges the delivery of media equipment, provides videotapes, and sees to any other logistical needs in connection with the activity.

After the activity is accomplished the instructor completes a feedback form and returns it the administrator. This feedback serves to confirm that the activity was completed and provide feedback to questions such as:

- Were the time estimates for the activity accurate?

- $\quad$ Are there any recommendations from the instructor?

- $\quad$ Did the activity run smoothly?

- $\quad$ Did most students seem to take the activity seriously?

- $\quad$ Did most students seem to learn something?

- $\quad$ Were students generally well behaved?

- Were most students cooperative?

- What is the instructor's sense as to whether the students appreciated the benefits of the activity?

- $\quad$ Are there any other comments about student reactions?

- $\quad$ Any additional comments or suggestions about the activity?

In many cases this feedback has been used to refine the activity and/or the documentation.

\section{Summary Of Activities By Course}

Introduction to Information Systems: Instruction in EXCEL, the Internet and information literacy. Students first take an online pretest to measure their information literacy. Then a worksheet (a series of questions that require using the Internet and various library electronic resources) is distributed and instruction is provided while students answer each question. Several weeks later in the semester an online posttest is given (virtually identical to the pretest) to measure the learning outcomes. Students are also taught to use Microsoft Excel software to develop simple models that reflect a "what-if" scenario involving a number of variables.

Principles of Marketing: Two short videos "The importance of business communications" and "Listening" (4) are shown and discussed. A handout "Tips on making presentations" is distributed. Each student is required to give a short presentation in the class to apply what they have learned. The student receives feedback on a form designed to correspond with the videos and handout. In a separate activity students are required to download (from the library's electronic reserve, ERes) and read a paper on "Making a Powerful First Impression" (3). They complete a written exercise, which includes composing a short self-introduction, and experience an in-class activity where each student practices his self-introduction on another.

Financial Accounting: Students are required to visit the web site of the International Accounting Standards Committee to download various pieces of information including one specified international standard that differs from the U.S. standard. The differences between IAS standards and those in the U.S. are discussed in class. In addition, each student is assigned a different country for which s/he must download information from the IAS site as well as maps of the country and its continent from Britannica Online.

Managerial Accounting: Students read a brief introduction that defines ethics and discusses the complexities of making ethical choices. Then a 30-minute video "Personal ethics and the future of the world" (2) is 
shown and discussed. The video proposes one way to go about making an ethical choice and effectively illustrates how a single individual's decision can impact the world.

Principles of Management: In this course a video on conflict resolution is shown and discussed. In addition, a semester case/project involving business ethics and PowerPoint presentation is assigned.

Statistics I: An exercise in information literacy and data mining is in the development stage.

Statistics II: Still in development, this activity will involve students downloading data from the Internet and conducting tests of hypotheses using EXCEL.

Microeconomics: Students participate in an in-class exercise and assignment to further their information literacy. The exercise is designed to familiarize students with various business and economics electronic databases, learn to articulate a search question and transform the question into a search statement suitable for database research, develop a more sophisticated search strategy and learn how to cite articles located in electronic databases.

Macroeconomics: In this course there is a semester long project that involves the use of Internet data on key economic indicators. Each student selects five countries, each from a different continent, and throughout the semester researches the economic indicators for those countries' as the indicators are covered in the course. At the end of the semester the student writes a short paper with a comparative analysis.

Financial Management: Students participate in a group case analysis that includes an ethical component. Each student is also required to write a short paper about the ethical dimensions (real, potential or hypothetical) of the case.

Business Law I: A semester project requires students to work in groups to identify, research, brief and report on recent instances of firms that have faced legal issues involving ethics, globalization and technology. There is also a presentation of the case.

Operations Management: Added to the course content are in-class lessons and demonstrations on solving five types of problems using EXCEL. Students are given test problems to study and practice two weeks before an exam conducted in a computer lab. Two of the problems involve EXCEL charts. This exam is part of the course grade.

Business Policy: Students are required to attend the Professional Networking/Etiquette Luncheon (see below) where they receive professional instruction on networking techniques and appropriate behavior in a business lunch setting. They are also strongly encouraged to participate in the SANDay day trip to New York City (see below) where they are allowed to choose two from a number of site visits and lunch with one of our alumni. They also view and discuss a video "Business Ethics: The Bottom Line". In their semester presentations they are expected to display a mature capability in communication skills, the use of presentation technology and ethical discernment.

\section{Special Activities}

SANDay (Student/Alumni Networking Day): This is an optional day trip via chartered busses to New York City open to juniors and seniors. Various site visits are arranged for morning and afternoon sessions from which students are given the opportunity to choose according to their interests and career objectives. Examples of site visits include a trade show at the Javits Center, stock exchanges, a permanent trade mart, the United Nations, the Federal Reserve Bank of NY, apparel manufacturers and retailers. Between the morning and afternoon sessions, students lunch in small groups with one of our alumni in Manhattan.

Professional Networking/Etiquette Luncheon: This is an optional activity open to all business majors (required for students in Business Policy). Students attend a luncheon with an outside speaker who gives tips on 
professional networking, business lunches, follow-up protocol and so on. Several professors give students extra credit for attending this activity.

\section{Conclusions}

Feedback is collected from instructors for each of the activities and this feedback is used to continually "tweak" the activities. In addition there is an ongoing search for better videos, more relevant articles and improved exercises to accomplish the goals of the program. Toward this end it is extremely important to engage the faculty as a rich resource for ideas.

To date there has not been any systematic feedback from the students, only a footer on all student handouts that invites comments and suggestions with the coordinator's e-mail address. Students have not responded to this invitation to any significant degree and a more structured method of assessing outcomes is clearly called for.

The crucial challenge for the future is to find a way of getting (and keeping) all professors on board with the initiative. It has become clear that the support of the majority is not enough. The success of this initiative requires administrative support in order to accomplish total compliance.

\section{References}

1. The challenge of change in business education, Ernst and Young Foundation (1995).

2. Personal ethics and the future of the world (1992) Film Ideas, Inc., 308 North Wolf Road, Wheeling, IL 60090

3. Pachter, Barbara and Brody, Marjorie, The Complete Business Etiquette Handbook, Prentice Hall (1995).

4. Importance of business communication" and "Listening" from the series Business Communications, Films for the Humanities \& Sciences, Box 2053, Princeton, NH 08543-2053.

Notes 